Academic Platform Journal of Engineering and Science

journal homepage: http://apjes.com/

\title{
Ayçiçek Yağı Metil Ester Karışımlarının DI Bir Dizel Motorunun Performans ve Emisyonlarına Etkisi
}

\author{
*1Vezir Ayhan, ${ }^{2}$ Serdar Tunca, ${ }^{1}$ İdris Cesur, ${ }^{1}$ İbrahim Özsert, ${ }^{1}$ Gökhan Ergen \\ ${ }^{1}$ Teknoloji Fakültesi, Makine Mühendisliği, Sakarya Uygulamalı Bilimler Üniversitesi, Türkiye, \\ vayhan@sakarya.edu.tr, \\ icesur@sakarya.edu.tr, \\ ozsert@sakarya.edu.tr, \\ gergen@sakarya.edu.tr, \\ ${ }^{2}$ Tüvtürk, Sakarya, Türkiye, serdartunca54@gmail.com,
}

Araştırma Makalesi

Geliş Tarihi: 04.07.2017

Kabul Tarihi: 07.08.2018

$\ddot{O} z$

Yenilenebilir alternatif yakıtlar, dizel motorlarından salınan HC, CO ve is emisyonlarını azalttıkları, aynı zamanda performansı da iyileştirdikleri için günümüzde araştırmacılar tarafından ilgi çeken konuların başında gelmektedir. Bu alternatif yakıtlar arasından biyodizel yüksek oksijen içeriği, dizel yakıtına yakın seviyede enerji içeriği, motorda herhangi bir modifikasyona ihtiyaç duyulmadan kullanılabilir olması ve düşük sülfür içeriği gibi birçok avantaja sahiptir. Bu çalışmada ayçiçek yağından transesterifikasyon yöntemiyle elde edilen metil ester-dizel karışımlarının DI bir dizel motorunun performans ve emisyonlarına etkisi deneysel olarak incelenmiştir. Motor deneyleri dizel ve farklı kütlesel oranlarda biyodizel-dizel B10 (\%10 Biyodizel+\%90 Dizel), B20 ve B50 karışımları ile tam yük şartlarında ve farklı motor devirlerinde gerçekleştirilmiştir. Elde edilen sonuçlardan, motorda B10 ve B20 karışımları kullanıldığında, motor efektif gücü ve torkunda standart duruma göre artmalar olurken, B50 karışımında azalmaların meydana geldiği tespit edilmiştir. Maksimum artma B20 yakıtı kullanımında elde edilmiştir. B20 kullanımı durumunda $\mathrm{HC}, \mathrm{CO}$ ve İs emisyonlarında dikkate değer oranda azalmaların meydana geldiği, NO emisyonlarında ise artmaların olduğu tespit edilmiştir.

Anahtar kelimeler: Ayçiçek yağı metil esteri, biyodizel-dizel karışımları, performans, emisyon

\section{The Effect of Sunflower Oil Methyl Ester Blends on a DI Diesel Engine Performance and Emissions}

\author{
${ }^{* 1}$ Vezir Ayhan, ${ }^{2}$ Serdar Tunca, ${ }^{1}$ İdris Cesur, ${ }^{1}$ İbrahim Özsert, ${ }^{1}$ Gökhan Ergen \\ *1Technology Faculty, Mechanical Engineering, Sakarya University of Applied Sciences, Turkey, vayhan@ sakarya.edu.tr, \\ icesur@sakarya.edu.tr, ozsert@sakarya.edu.tr, gergen@sakarya.edu.tr \\ ${ }^{2}$ Tüvtürk, Sakarya, Turkey, serdartunca54@gmail.com
}

\begin{abstract}
Renewable alternative fuels have forefront of researchers' interest today in view of reduction $\mathrm{HC}$, $\mathrm{CO}$ and soot emissions and as the same time improvement of the performance in diesel engines. Among these alternative fuels, biodiesel has a lot of advantages such as high oxygen content, utility without modification near-diesel energy content and low sulfur content. In this study, the effects of sunflower oil methyl ester obtained by the transesterification methods diesel blends on the DI diesel engine performance and emission parameters were investigated experimentally. Experimental studies were carried out using as a fuel diesel and mass-produced diesel-biodiesel blends B10 (10\% biyodisel+90\% pure diesel), B20 and B50 at under full load conditions and different engine speeds. It has been obtained that when the B10 and B20 of biodiesel blends were used in engine as a fuel engine effective power and torque increases, but B50 blends using engine effective power and torque decreases according to the standard situation. The maximum increase was achieved with the use of B20 blends. It has been determined that
\end{abstract}

*Sorumlu Yazar: Vezir Ayhan, Teknoloji Fakültesi, Makine Mühendisliği, Sakarya Uygulamalı Bilimler Üniversitesi, Türkiye, vayhan@sakarya.edu.tr, Tel:0 2642956530 
if this fuel (B20) was used, $\mathrm{HC}, \mathrm{CO}$ and smoke emissions considerable decreased and NO emission increased according to standard engine values.

Keywords: Sunflower methyl ester, biodiesel-diesel blends, performance, emission

\section{GİRIŞ}

Hızla artan nüfus, gelişen sanayi ve modernizasyon dünya genelinde enerjiye olan ihtiyacı sürekli arttırmaktadır. Artan enerji ihtiyacı var olan kaynaklar ile karşılanamamaktadır. Birçok gelişmiş ülke artan enerji ihtiyacını karşılayabilmek için ham petrol ithal etmektedir[1]. Diğer taraftan petrol kaynakları rezervlerinin azalması, petrol fiyatlarının yükselmesi, yaşanan petrol krizleri ve motorlardan salınan kirletici emisyon değerlerine getirilen yasal sinırlamalar araştırmacı ve imalatçıları yenilenebilir alternatif yakıtlara yönlendirmiştir. Biyodizel, dizel motorlarında kullanılan en popüler yenilenebilir alternatif yakıttır[2-4]. Bitkisel veya hayvansal yağlardan farklı yöntemlerle elde edilebilen biyodizelin, oksijen içeriği yükssek, zehirsiz, dizel yakıta yakın yakıt özellikleri, içerisinde sülfür barındırmaması ve motorda herhangi bir modifikasyona ihtiyaç duyulmadan kullanılabilir olması gibi üstünlükleri nedeni ile diğer alternatif yakıtlara göre daha fazla ilgi görmektedir[5-7]. Ülkemizin bir tarım ülkesi olduğu düşünüldüğünde ve yılda yaklaşık 300 bin ton bitkisel yağın atıldığı dikkate alındığında biyodizelin ülke ekonomisi açısından sağlayacağı katkı oldukça yüksektir. Enerji ihtiyacının karşılanmasında yerel kaynakların kullanılması, var olan kaynakların ise verimli bir şekilde kullanımı, kaynak çeşitliliğinin ve sürekliliğin sağlanmasının yanında taşıt kaynaklı hava kirliliğinin azaltılması günümüzde teşvik edilen en önemli konulardan biridir[8].

Bitkisel veya hayvansal yağların farklı yöntemler ile viskozite değerlerinin düşürülmesi yönündeki çalışmalar biyodizel üretimi çalışmalarının çoğunluğunu oluşturmaktadır[9]. Viskoziteyi düşürmede farklı yöntemler kullanılmakla birlikte en etkili yöntem transesterifikasyon metodudur. Transesterifikasyon metodu; bitkisel veya hayvansal yağların metil alkol ve etil alkol gibi monohidrik bir alkol ve katalizör ile reaksiyon gerçekleştirerek yağ asidi esteri ve gliserin elde etmek için uygulanan esterleştirme işlemidir[10]. $\mathrm{Bu}$ işlemde reaksiyonların hızlanması için katalizör kullanılmaktadır. En yaygın kullanılan katalizörler sodyum hidroksit $(\mathrm{NaOH})$ ve potasyum hidroksittir $(\mathrm{KOH})$ [10-13].

Yeniden esterleştirme işlemi sonucunda elde edilen biyodizelin kimyasal yapısı dizel yakıtından farklıdır. En önemli üstünlüğü oksijen içeriğine sahip olmasıdır. Yüksek oksijen içeriği sayesinde dizel motorlarında karışım olarak kullanılması sonucunda yanma verimini arttırdığı, performans parametrelerini iyileştirdiği ve $\mathrm{CO}, \mathrm{HC}$ ve is emisyonlarında azalma sağladığı bilinmektedir.

Literatürde farklı bitkisel veya hayvansal yağlardan elde edilmiş biyodizel-dizel karışımlarının dizel motorlarında yakıt olarak kullanılması üzerine pek çok çalışma yapılmıştır[14-26]. Çalışmalar genel olarak incelendiğinde düşük oranlarda biyodizel-dizel karışımlarının motorda yakıt olarak kullanılması durumunda motor torkunun ve efektif gücün arttığı görülmektedir. Bazı araştırmacılar \%20 biyodizel karışımı (B20) kullanımında motor torkunda meydana gelen artmanın daha yüksek olduğunu tespit etmişlerdir[14,16,22-25].Cesur ve ark.[8], tek silindirli, DI bir dizel motorunda tavuk yağından transesterifikasyon yöntemi ile elde ettikleri biyodizel-dizel karışımlarını (B10, B20 ve B50) motorda yakıt olarak kullanmışlardır. Tam yük şartlarında yaptıkları deneysel çalışmalar sonucunda, B10 ve B20 kullanımında standart dizele göre motor performans parametrelerinde iyileşmelerin meydana geldiğini, B50 de ise bir miktar kötüleşmelerin olduğunu tespit etmişlerdir.

Biyodizel karışımlarının kullanılması durumunda $\mathrm{HC}$, is ve $\mathrm{CO}$ emisyonlarında azalmaların olduğunu, $\mathrm{NOx}$ ' da ise artmaların meydana geldiğini saptamışlardır. İlker ve ark.[10], tek silindirli, ön yanma odalı bir dizel motorunda ayçiçek yağından elde ettikleri metil esteri B50 karışım ve B100 olarak kullanmış, motor performans ve emisyonlara etkisini deneysel olarak incelemişlerdir. Çalışma sonuçlarında B50 ve B100 kullanımında motor performans parametrelerinin standart yakıta göre kötüleştiğini, CO emisyonlarında ise azalmaların meydana geldiğini tespit etmişlerdir.

Yücesu ve ark.[27], farklı bitkisel yağ ve bitkisel yağlardan elde edilen metil esterleri bir dizel motorunda kullanarak tam yük ve kısmi yük şartlarında motor performans ve emisyon parametrelerine etkilerini incelemişlerdir. Bitkisel yă kullanımı durumunda motor performans, NOx ve is emisyonlarının dizel yakıta göre kötüleştiğini, metil esterlerin kullanılması durumunda ise motor performansının arttığını belirtmişlerdir.

Rakopoluos ve ark.[28], aşırı doldurmalı direkt enjeksiyonlu bir dizel motorunda ayçiçek ve pamuk yağından elde ettikleri metil esterler- dizel karışımlarını (B10 ve B20) yakıt olarak kullanmış ve elde etikleri sonuçları standart dizel yakıt verileriyle karşılaştırmışlardır. Çalışmaları sonucunda, biyodizel karışımları kullanılması durumunda motor gücünde dikkate değer bir değişme meydana gelmezken, özgül yakıt sarfiyatının, NOx ve HC emisyonlarının arttığını $\mathrm{CO}$ emisyonlarının ise azaldığını tespit etmişlerdir. Kaplan ve ark.[29], 4 silindirli bir dizel motorunda transesterifikasyon yöntemi ile elde ettikleri ayçiçek yağı metil esterini yakıt olarak kullanmışlardır. Çalışmaları sonucunda dizel yakıtına göre özgül yakıt tüketiminin arttığını, is emisyonların da ise azalmaların meydana geldiğini ileri sürmüşlerdir.

Bu çalışmada ayçiçek yağından transesterifikasyon yöntemi ile elde edilen metil esterin farklı oranlarda dizel yakıtı ile 
karıştırılması ile elde edilen biyodizel karışımlarının (B10, B20 ve B50) 4 zamanlı bir dizel motorunda kullanımının motor performans parametreleri ve emisyon karakteristiklerine etkileri incelenmiştir. Elde edilen veriler standart dizel verileriyle karşılaştırmalı olarak verilmiştir.

\section{MATERYAL VE METOT}

\subsection{Ayçiçek Yağı Metil Esterinin Üretilmesi}

Ayçiçek yağından biyodizel eldesinde transesterifikasyon yöntemi kullanılmıştır. Alkol olarak \%99 saflık değerinde metanol, katalizör olarak ise $\mathrm{KOH}$ kullanılmıştır. Yağ, alkol ve katalizör ağılıkları $0.001 \mathrm{~g}$ hassasiyetinde hassas terazi ile ölçülmüştür. Alkol ve katalizör ağırlıkları ölçülerek cam bir kap içerisinde katalizörün alkol içerisinde tamamen çözünmesi sağlanmıştır. Daha sonra ayçiçek yağı istenilen sıcaklık değerine 1sitılmış ve hazırlanan alkol-katalizör karışımı yağın içerisine katılmıştır.

Transesterifikasyon reaksiyonlarının gerçekleştirilmesi için karışım sıcak su banyosu içerinde 1 saat boyunca $600 \mathrm{~d} / \mathrm{d}$ karıştırılmıştır. Daha sonra ester ve gliserinin ayrışması için ayrıştırma kabına konulmuş ve ester elde edilmiştir. Elde edilen ester, saf su ile yıkanıp kurutma işlemine tabi tutulmuştur. Çalışmada kullanılan yakıtların özellikleri Tablo 1' de verilmiştir.

Tablo 1. Dizel ve biyodizelin özellikleri

\begin{tabular}{lll}
\hline Özellik & Dizel & Biyodizel \\
\hline Yoğunluk $\left(\mathrm{kg} / \mathrm{m}^{3}\right)$ & $825-840$ & 880 \\
Gizli Buharlaşma Isısı $(\mathrm{kJ} / \mathrm{kg})$ & 250 & - \\
Setan Sayısı & 57 & 46,8 \\
Alt Isıl Değeri $(\mathrm{MJ} / \mathrm{kg})$ & 42,6 & 39,5 \\
Kinematik Viskozitesi $\left(40{ }^{\circ} \mathrm{C}\right)$ & 2,6 & 4.7 \\
$\left(\mathrm{~mm}^{2} / \mathrm{s}\right)$ & & \\
Kaynama Noktası $\left({ }^{\circ} \mathrm{C}\right)$ & $180-360$ & - \\
Tutuşma Sicaklığ1 $\left({ }^{\circ} \mathrm{C}\right)$ & 250 & 125 \\
\hline
\end{tabular}

\subsection{Deneysel Çalışmalar}

Deneylerde tek silindirli, su soğutmalı, doğal emişli, SüperStar marka direkt enjeksiyonlu bir dizel motoru kullanılmıştır. Çalışmada kullanılan motorun özellikleri Tablo 2' de verilmiştir.

Efektif gücün ölçülebilmesi için, deney motoru $20 \mathrm{~kW}$ ' lık elektrikli tip bir dinamometreye bağlanmıştır. Dinamometre kuvvet kolunda $0,1 \mathrm{~kg}$ hassasiyetinde "S" tipi yük hücresi kullanılmıştır. Deneylerden önce yük hücresi hassas bir şekilde kalibre edilmiştir. Deneyler tam yük şartlarında ve $1000,1300,1600,1900$ ve $2200 \mathrm{~d} / \mathrm{d}$ motor hizlarında gerçekleştirilirmiştir. Optimum statik püskürtme avansının tespiti için deneysel çalışmalar yapılmış motor performansı açısından en uygun statik püskürtme avansı değerinin üst ölü noktadan önce $34^{\circ}$ krank mili açısı olduğu tespit edilmiş ve deneyler bu avans değerinde gerçekleştirilmiştir. Şekil 1' de deney düzeneğinin şematik şekli görülmektedir $[8,14]$.

Tablo 2. Deney motorunun teknik özellikleri

\begin{tabular}{ll}
\hline Motor Tipi & Süper Star \\
\hline Piston Çapı [mm] & 108 \\
Strok [mm] & 110 \\
Silindir Sayısı & 1 \\
Strok Hacmi [dm $\left.{ }^{3}\right]$ & 1 \\
Güç, 2200 d/d, [kW] & 13 \\
Enjektör Açma Basıncı [bar] & 175 \\
Püskürtme Avansı [Krank Açıs1] & 34 \\
Sıkıştırma Oranı & 17,5 \\
Maksimum Devir [d/d] & 2500 \\
Soğutma Tipi & Su \\
Püskürtme Tipi & Direkt Enjeksiyon \\
Piston Tipi & Çanak Piston \\
\hline
\end{tabular}

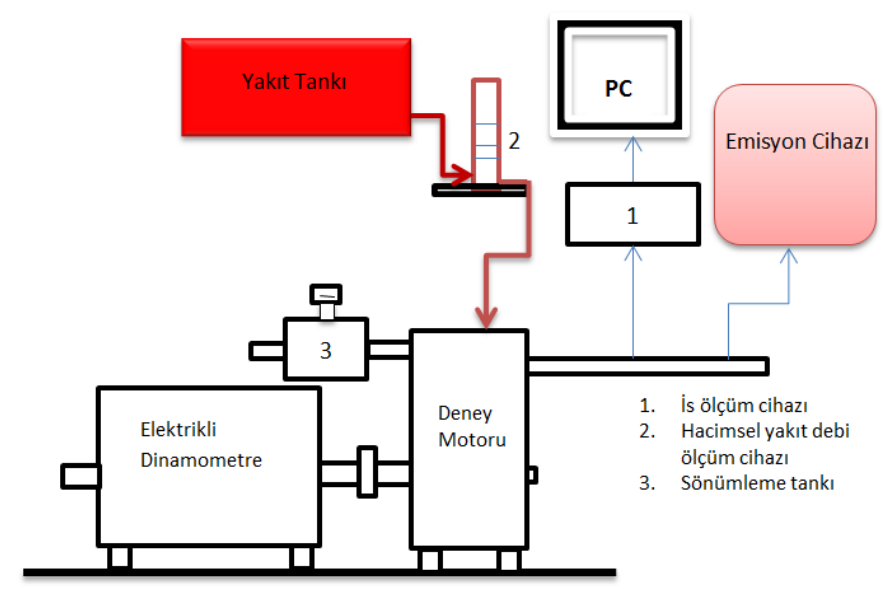

Şekil 1. Deney düzeneği

Egzoz emisyonlarının ölçülmesinde ( $\left.\mathrm{HC}, \mathrm{CO}, \mathrm{NO}, \mathrm{O}_{2}\right)$ BOCSH marka BEA modeli gaz analiz cihazı, is emisyonlarının ölçülmesinde BİLSA marka is ölçüm cihazı kullanılmıştır.

Yakıt sarfiyatı ölçümü 25 ve $50 \mathrm{~cm}^{3}$, lük cam hazneli hacimsel yakıt ölçüm sistemi ile gerçekleştirilmiştir. Soğutma sistemi kapalı sistem olup, deneylerde soğutma suyu çıkış sıcaklığı $70{ }^{\circ} \mathrm{C}$ değerinde tutulmuştur. Hava sarfiyatı ölçümünde orifis plaka -sönümleme tank1 sistemi kullanılmıştır.

\subsection{Belirsizlik Analizi}

Sunulan çalışmada kullanılan cihazlar ve ölçüm hassasiyetleri Tablo 3' de verilmiştir. 
Tablo 3. Deney düzeneğinde kullanılan cihazların özellikleri ve ölçüm hassasiyetleri

\begin{tabular}{|c|c|c|c|c|}
\hline $\begin{array}{c}\text { Ölçülen } \\
\text { parametreler }\end{array}$ & Birim & $\begin{array}{l}\text { Ölçüm } \\
\text { aralığı }\end{array}$ & Ölçme aleti & $\begin{array}{c}\text { Ölçüm } \\
\text { hassasiyeti }\end{array}$ \\
\hline Motor Devri & $\mathrm{d} / \mathrm{d}$ & $0-9999$ & $\begin{array}{c}\text { Dijital } \\
\text { takometre }\end{array}$ & $1 \mathrm{dev} / \mathrm{dak}$ \\
\hline $\begin{array}{l}\text { Egzoz } \\
\text { sicaklığ1 }\end{array}$ & ${ }^{\circ} \mathrm{C}$ & $0-1000$ & $\mathrm{Ni}-\mathrm{Cr}-\mathrm{Ni}$ & $1{ }^{\circ} \mathrm{C}$ \\
\hline $\begin{array}{l}\text { Soğutma suyu } \\
\text { giriş-çıkış ve } \\
\text { ortam } \\
\text { Sicaklığ }\end{array}$ & ${ }^{\circ} \mathrm{C}$ & 0-999 & Fe-Konst. & $1^{\circ} \mathrm{C}$ \\
\hline $\begin{array}{l}\text { Yakıt tüketim } \\
\text { zamanı }\end{array}$ & $\mathrm{s}$ & - & Kronometre & $0,001 \mathrm{~s}$ \\
\hline $\begin{array}{l}\text { Fren terazi } \\
\text { kuvveti, } S \text { tipi } \\
\text { yük hücresi }\end{array}$ & $\mathrm{Kg}$ & $0-100$ & $\begin{array}{c}\text { Elektrikli } \\
\text { Dinamometre, } \\
\text { Yük hücresi }\end{array}$ & $0,1 \mathrm{Kg}$ \\
\hline $\begin{array}{l}\text { Hava tüketim } \\
\text { miktarı }\end{array}$ & $\mathrm{mmSS}$ & $0-100$ & $\begin{array}{c}\text { Eğik } \\
\text { manometre }\end{array}$ & $1 \mathrm{~mm}$ \\
\hline $\begin{array}{l}\text { Karbon } \\
\text { monoksit } \\
(\mathrm{CO})\end{array}$ & $\begin{array}{c}\% \\
\text { hacimsel }\end{array}$ & $\begin{array}{l}\% 0- \\
10,0\end{array}$ & $\begin{array}{c}\text { BOCSH- } \\
\text { BEA }\end{array}$ & $\% \pm 0,055$ \\
\hline $\begin{array}{l}\text { Hidrokarbon } \\
(\mathrm{HC}), \mathrm{ppm}\end{array}$ & ppm & 0-9999 & $\begin{array}{l}\text { BOCSH- } \\
\text { BEA }\end{array}$ & $\begin{array}{l}\text { Ölçülen } \\
\text { değerin } \\
\% 5 \% \text { i }\end{array}$ \\
\hline $\begin{array}{l}\text { Azot oksit } \\
(\mathrm{NO}), \mathrm{ppm}\end{array}$ & ppm & $0-5000$ & $\begin{array}{l}\text { BOCSH- } \\
\text { BEA }\end{array}$ & $\begin{array}{l}\text { Ölçülen } \\
\text { değerin } \\
\% 55^{\prime} i\end{array}$ \\
\hline $\begin{array}{l}\text { Duman } \\
\text { Koyuluğu }\end{array}$ & $\%$ & $0-100$ & $\begin{array}{c}\text { Bilsa } \\
\text { Mod5000 }\end{array}$ & $\% 1$ \\
\hline
\end{tabular}

Deney sonuçlarını neticesinde hesaplanan motor performans parametrelerinde $\% 1$ ile $\% 1,5$ değişen oranlarda belirsizlikler mevcuttur (Tablo 4).

Tablo 4. Sistematik ve rasgele hatalara göre hesaplanmış toplam belirsizlikler

\begin{tabular}{lc}
\hline & Toplam Belirsizlik, \% \\
\hline Özgül Yakıt sarfiyatı, g/kWh & 1,5 \\
Moment, Nm & 1,0 \\
Efektif güç, kW & 1,3 \\
\hline
\end{tabular}

\section{SONUCLAR}

\subsection{Motor Performans Parametreleri}

Şekil 2 ve 3' de sırasıyla tam yük şartlarında farklı motor devirlerinde dizel, B10, B20 ve B50 kullanılarak elde edilen motor tork ve efektif güç değerlerinde meydana gelen değişimler görülmektedir. Şekillerden de görüldüğü gibi B10 ve B20 kullanımında moment ve efektif güçte standart duruma göre artmalar meydana gelirken B50 kullanımında azalmaların olduğu tespit edilmiştir.

Standart durumda $1300 \mathrm{~d} / \mathrm{d}$ motor devrinde 61,6 Nm olarak ölçülen motor tork değeri, B10 kullanımında $61.7 \mathrm{Nm}$ ve B20 kullanıminda ise 62,1 $\mathrm{Nm}$ ve B50' de ise $61,2 \mathrm{Nm}$ olarak ölçülmüştür. Standart durumda $2200 \mathrm{~d} / \mathrm{d}$ motor hızında maksimum $12,42 \mathrm{~kW}$ olarak ölçülen efektif güç değeri B10' da 12,45 kW, B20' de 12,5 kW, B50 kullanımında ise 12,4 olduğu tespit edilmiştir. B10 ve B20 kullanımında standart duruma göre motor tork ve efektif güçte artmaların meydana gelmesi, biyodizelin oksijence zengin bir kimyasal yapıya sahip olmasına bağlı olarak yanma verimini iyileştirmesinden kaynaklanmaktadır. Aynı zamanda biyodizelin yoğunluğunun dizele göre yüksek olması bir çevrimde silindir içerisine gönderilen toplam kütlesel enerji miktarının artmasına sebep olmasından kaynaklandığı düşünülmektedir. Ancak karışım içerindeki biyodizel arttıkça (B50) biyodizelin ısıl değerinin dizele göre düşük olmasından dolayı B10 ve B20' de artmalara neden olan etkenlerin etkisi karışımın 1sıl değerinin fazla düşmesinden dolayı etkili olamamakta ve performans düşmektedir.

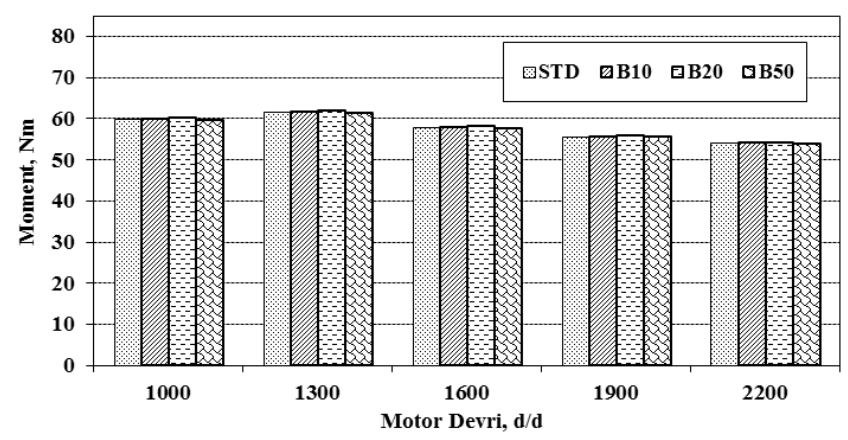

Şekil 2. Motor döndürme momenti değişimleri

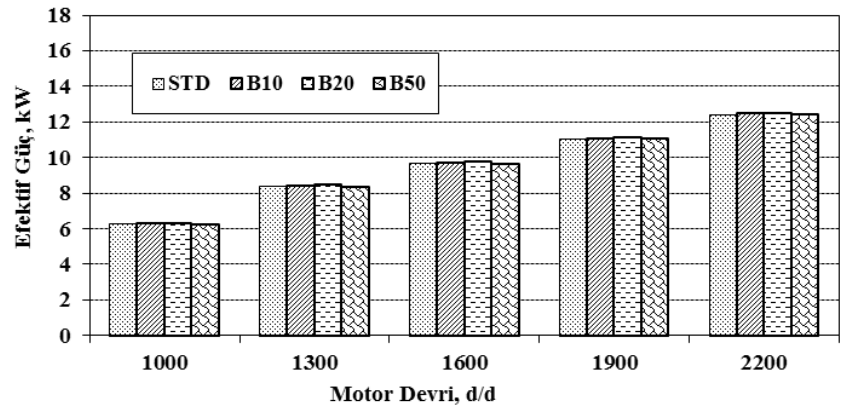

Şekil 3. Motor efektif güç değişimleri

Dizel, B10, B20 ve B50 karışımlarının kullanılması durumunda elde edilen Özgül yakıt sarfiyatındaki (ÖYS) değişimleri Şekil 4'de görülmektedir. Şekilden de görüldüğü gibi motorda biyodizel karışımları kullanılması durumunda standart motor verilerine göre özgül yakıt sarfiyatında tüm karışım oranlarında ve test devirlerinde artmaların meydana geldiği tespit edilmiştir.

Standart durumda $254,2 \mathrm{gr} / \mathrm{kWh}$ olarak hesaplanan ÖYS, B10 kullanımında 256,7 gr/kWh, B20 kullanımında 256,5 gr/kWh, B50 kullanımında ise 258.8 olarak hesap edilmiştir. ÖYS' da B20 kullanımında diğer karışım oranlarına göre daha az artma miktarı elde edilmiştir. Biyodizel karıșımları kullanımında standart duruma göre maksimum değişim \% 1,7 olarak hesap edilmiştir. Biyodizelin yoğunluğunun dizele göre yüksek olması ve ısıl değerinin ise düşük olması nedeni ile bir çevrimde pompa plancer üzerindeki hacimden silindire enjekte edilen kütlesel yakıt miktarı artmaktadır. Bu da ÖYS' da artmalara neden olmaktadır. 


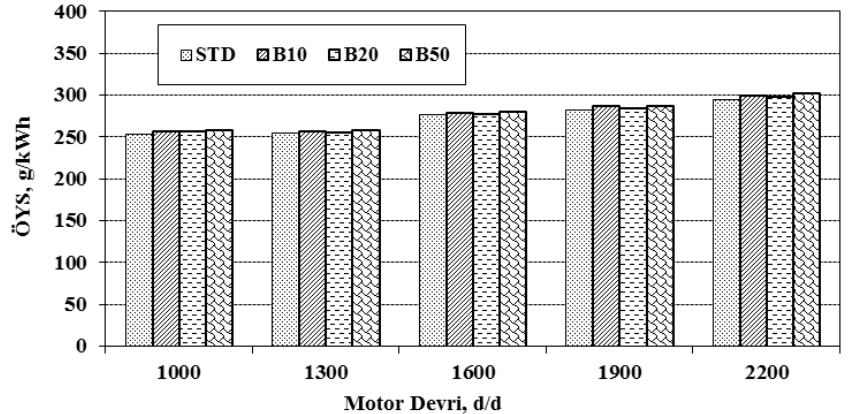

Şekil 4. ÖYS değişimleri

Şekil 5' de tam yük şartlarında, farklı motor devirlerinde dizel, B10, B20 ve B50 kullanılarak elde edilen efektif verim değerleri görülmektedir.

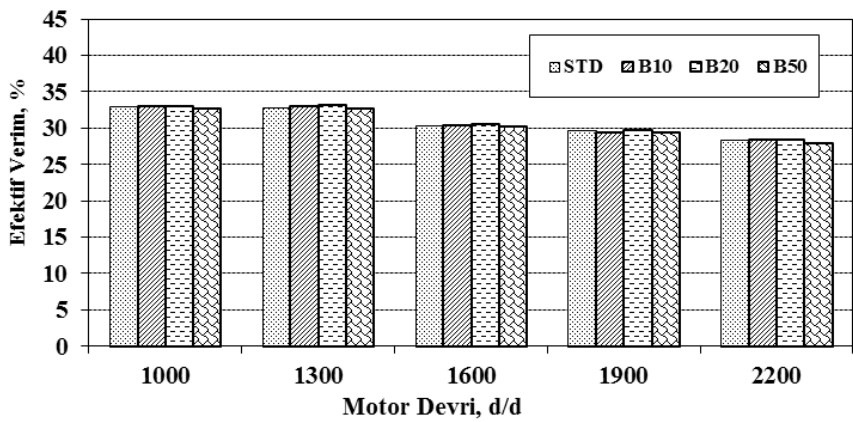

Şekil 5. Motor efektif verim değişimleri

Şekilden de görüldüğü gibi motorda B20 kullanıldığında bütün motor devirlerinde standart duruma göre efektif verim değerlerinde artmaların olduğu tespit edilmiştir. Maksimum değişim oranı \%1,3 olarak hesaplanmıştır. B10 kullanımında düşük motor devirlerinde efektif verim değerlerinde artmalar, yüksek motor devirlerinde ise standart duruma göre azalmaların meydana geldiği görülmüştür. B50 kullanımında ise tüm motor devirlerinde standart duruma göre azalmaların olduğu saptanmıştır.

\subsection{Emisyon Karakteristikleri}

Motorda dizel, B10, B20 ve B50 yakıtları kullanılarak tam yük şartlarında ve farklı motor hızlarında ölçülen NO değerlerinde meydana gelen değişism oranları Şekil 6' da verilmiştir. Şekil incelendiğinde, biyodizel karışımlı yakıtlar motorda kullanıldığında standart duruma göre NO emisyonlarında artmaların meydana geldiği görülmektedir. Karışım içerisindeki biyodizel oranı arttıkça NO emisyonlarındaki artma oranı da yükselmiştir. Maksimum artma oranı B50 kullanımında \%11 olarak ölçülmüştür. NO emisyonlarının oluşmasını etkileyen ana mekanizmalardan biri silindir içerisinde meydana gelen yüksek sicaklık değerleri diğeri ise, hava/yakıt oranıdır. Biyodizel kullanımında oksijen içeriğine bağlı olarak yanma verimi artmakta ve silindir içi ulaşılan maksimum sicaklık değerlerinde artmalar meydana gelmektedir. Aynı zamanda standart duruma göre motor biraz daha fakir karışım bölgesinde çalıştığından NO oluşum oranı artmaktadır.

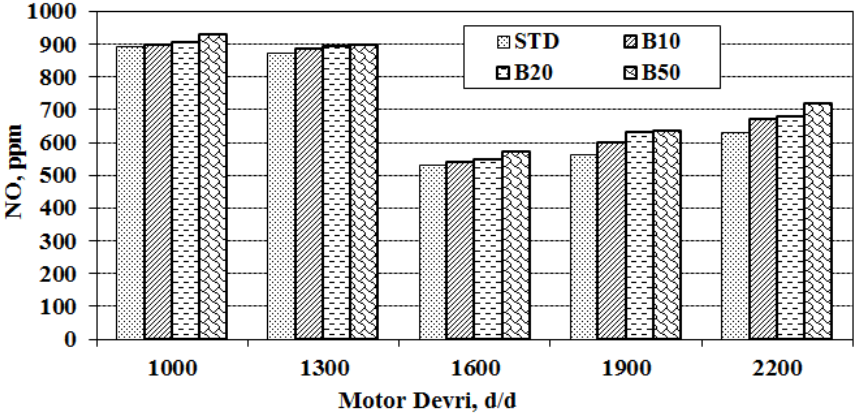

Şekil 6. NO emisyonları değişimi

Şekil 7' de dizel, B10, B20 ve B50 kullanılarak elde edilen is emisyonu değerlerindeki değişimler görülmektedir.

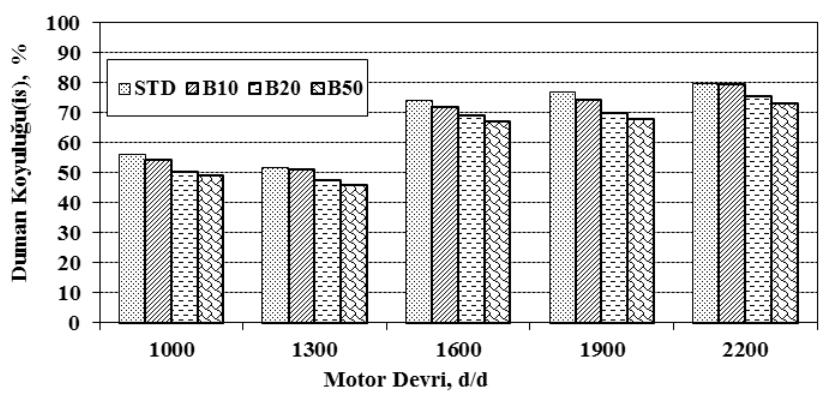

Şekil 7. İs emisyonları değişimi

Dizel motorlarının yüksek hava fazlalık katsayısı değerlerinde çalışmasına rağmen is emisyonlarının oluşmasının nedeni, silindir içerisinde yakıt/hava karışımının yeterince karışamaması ve lokal zengin karışım bölgelerinin oluşmasından kaynaklandığı bilinmektedir. Ayrıca yanma için yeterli zamanın kalmaması da is emisyonlarının oluşumunu etkileyen diğer bir etkendir. Şekil incelendiğinde oksijen içeriği yüksek olan biyodizel karışımları kullanıldığında standart duruma göre is emisyonlarında azalmaların meydana geldiği görülmektedir. Karışım içerindeki biyodizel oranı arttıkça standart duruma göre is emisyonlarında azalma miktarı da artmıștır. Maksimum azalma miktarı B50 kullanımında elde edilmiş ve standart duruma göre \%14' lere varan oranlarda azalmalar elde edilmiștir. Maksimum momentin elde edildiği B20 kullanımında ise maksimum azalma oranı $\% 8$ mertebelerinde olmuştur.

Şekil 8' de tam yük şartlarında ve farklı motor devirlerinde dizel, B10, B20 ve B50 yakıtları kullanılarak ölçülen CO emisyonu değerleri verilmiştir. Şekil incelendiğinde standart duruma diğer yakıtların kullanımında $\mathrm{CO}$ emisyonlarında tüm motor devirlerinde azalmaların olduğu görülmektedir. Karışım içerisindeki biyodizel oranı arttıkça CO emisyonlarında meydana gelen azalma miktarı da artmıştır. Maksimum azalma B50 kullanımında elde edilmiştir. Kısmi eksik yanma ürünü olan $\mathrm{CO}$ emisyonlarının biyodizel karışımları kullanımında azalmasının sebebi motorun biyodizel oksijen içeriğinden dolayı daha fakir karışımlarla çalışmasından kaynaklanmaktadır. 


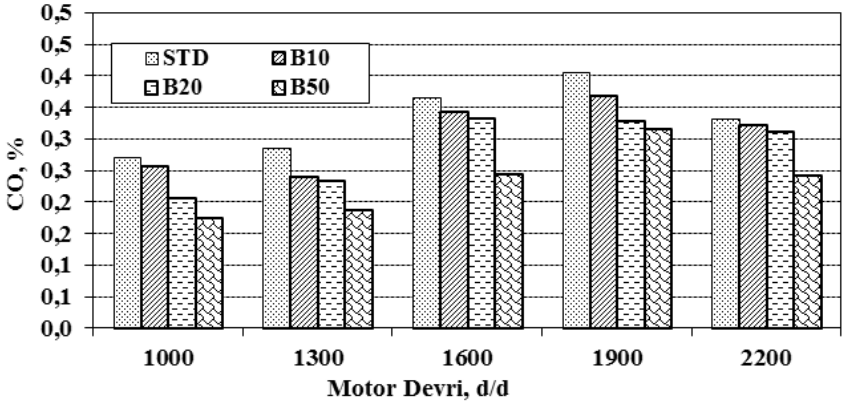

Şekil 8. CO emisyonları değişimi

Motorda dizel, B10, B20 ve B50 yakıtları kullanılarak tam yük şartlarında ve farklı motor hızlarında ölçülen HC emisyon değerleri Şekil 9' da verilmiştir.

Şekil incelendiğinde standart duruma göre biyodizel karışımları kullanıldığında HC emisyon değerlerinde özellikle düşük motor devirlerinde azalmalar gözlemlenirken, yüksek motor devirlerinde artmalarında meydana geldiği görülmüştür. Biyodizel karışımlarının kullanılması durumunda setan sayısının standart duruma göre artması HC emisyonlarının azalmasını sağlayacaktır. Ayrıca, yanma veriminin artması ve oksijen içeriğinin yükselmesi $\mathrm{HC}$ emisyonlarını azaltacaktır.

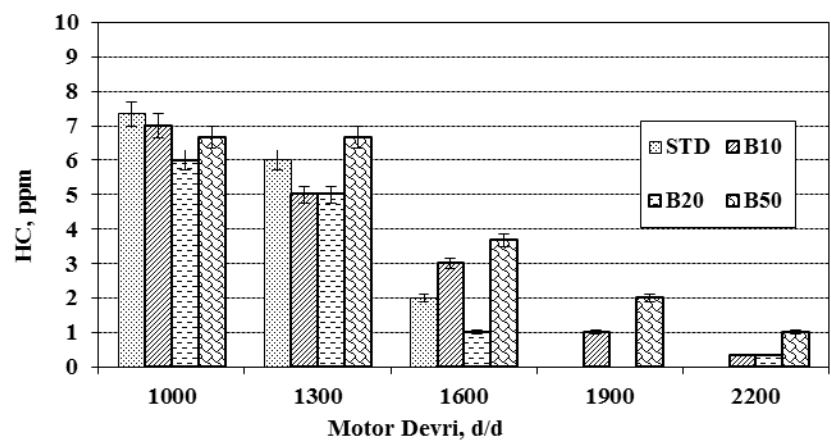

Şekil 9. HC emisyonları değişimi

\section{DEĞERLENDİRME VE TARTIŞMA}

Çalışmada ayçiçek yağından transesterifikasyon yöntemi ile elde edilen metil esterin B10, B20 ve B50 oranlarında direkt enjeksiyonlu bir dizel motorunda kullanımının motor performans parametreleri ve emisyon değerlerine etkileri deneysel olarak incelenmiștir. Çalışma sonucunda standart duruma göre;

1.Motor döndürme momenti ve efektif gücün $\mathrm{B} 10$ ve $\mathrm{B} 20$ karışım oranlarında arttı̆̆ı, B50 karıșım oranın da ise azaldığ 1 tespit edilmiştir. Maksimum artma miktarı B20 kullanımında meydana gelmiştir.

2.ÖYS' da biyodizel karışımları kullanılması durumunda bir miktar artmaların meydana geldiği, karışım içerisindeki biyodizel oranının arttıkça ÖYS' nında arttığı tespit edilmiştir.

3.Efektif verimde B20 kullanımında tüm motor devirlerinde artmaların meydana geldiği, B50 kullanımında ise azalmaların gözlemlendiği saptanmıştır.
4.NO emisyonlarında biyodizel karışımları kullanılması durumunda artmaların meydana geldiği gözlemlenmiştir. 5.İs emisyonlarında biyodizel karışımları kullanılması durumunda dikkate değer oranda azalmaların meydana geldiği saptanmıştır.

6.CO emisyonlarında biyodizel karışımları kullanılması durumunda azalmaların meydana geldiği tespit edilmiştir.

7.HC emisyonlarında biyodizel karışımlarının kullanılması durumunda düşük motor devirlerinde azalmaların, yüksek motor devirlerinde ise bazı karışım oranlarında artmaların olduğu tespit edilmiştir.

\section{TEŞEKKÜR}

Bu çalışma Sakarya Üniversitesi, Bilimsel Araştırma Projeler Koordinatörlüğü tarafından (FBYLTEZ-2012-5001-046) desteklenmiştir. Maddi desteklerinden dolayı SAÜ, BAPK' a teşekkür ederiz.

\section{KAYNAKÇA}

[1].M.M. Hasan, M.M Rahman, "Performance and emission characteristics of biodiesel-diesel blend and environmental and economic impacts of biodiesel production: A review", Renewable and Sustainable Energy Reviews, vol. 74, pp. 938-948, 2017.

[2].B. He, Y.Shao, Y. Ren, J.Li, Y. Cheng, "Continuous biodiesel production from acidic oil using a combination of cation- and anion-exchange resins", Fuel Processing Technology, vol. 130, pp. 1-6, 2015.

[3].M. Çanakci, "Performance and emissions characteristics of biodiesel from soybean oil", P. I. Mech. Eng D-J. Aut. Vol. 219, pp. 915-922, 2005.

[4].O.Özener, L.Yüksek, A.T.Ergenç, A.T. M.Özkan, "Effects of soybean biodiesel on a DI diesel engine performance, emission and combustion characteristics", Fuel, vol. 115, pp. 875-883, 2014.

[5].M.Sundaresan, S.Chandrasekaran, P.T. Porai, "Analysis of combustion, performance and emission characteristics of blends of methyl esters of jatropha oil (MEJ) in DI diesel engine", SAE Technical Paper, 2007.

[6].M.S.Graboski, R.L. McCormick, "Combustion of fat and vegetable oil derived fuels in diesel engines", Prog Energy Combust Sci, vol. 24, pp. 125-64, 1998.

[7].A.Monyem, J.H. Van Gerpen, "The effect of biodiesel oxidation on engine performance and emissions", BiomassBioenergy, vol. 20, pp. 317-25, 2001.

[8].İ.Cesur, V.Ayhan,P.Parlak, "Bir Dizel Motorunda Tavuk Yağı Metil Esteri Kullanılmasının Performans Ve Emisyonlara Etkisi”, 10. Uluslararası Yanma Sempozyumu, Sakarya/ Türkiye, 09-10 Ekim 2008.

[9].C.Haşimoğlu, "Düşük Isı Kayıplı Bir Dizel Motorunda Biyodizel Kullanılmasının Performans ve Emisyon Parametrelerine Etkisi" Sakarya Üniversitesi Fen Bilimleri Enstitüsü, Doktora Tezi, Sakarya 2005.

[10]. İ.Sugozu, F.Aksoy,Ş.A.Baydır, "Bir Dizel Motorunda Ayçiçeği Metil Esteri Kullanımının Motor Performans ve Emisyonlarına Etkisi”, Makine Teknolojileri Elektronik Dergisi, Cilt: 6, No: 2, pp.49-56, 2009. 
[11]. D.Y.C.Leung, Y.Guo, "Transesterification of neat and used frying oil: Optimization for biodiesel production", Fuel Processing Technology, vol. 87, pp. 883-890, 2006.

[12]. H.S.Yücesu, R.Altın, S.Cetinkaya, "Dizel Motorlarında alternatif yakıt olarak bitkisel yağ kullanımının deneysel incelenmesi", Turkish Journal Enginering Environment Science, vol. 25, pp. 39-49, 2001.

[13]. H.Raheman, A.G.Phadatare, "Diesel engine emissions and performance from blends of karanja methyl ester and diesel", Biomass and Bioenergy, vol. 27, pp. 393 397, 2004.

[14]. A.Parlak, V.Ayhan, İ.Cesur, G.Kökkülünk, "Investigation of the effects of steam injection on performance and emissions of a diesel engine fuelled with tobacco seed oil methyl ester", Fuel Processing Technology, vol. 116, pp. 101-109, 2015.

[15]. M.Karabektaş, G.Ergen, M.Hoşöz, "The effects of preheated cottonseed oil methyl ester on the performance and exhaust emissions of a diesel engine", Applied Thermal Engineering, vol. 28, pp. 2136-2143, 2008.

[16]. A.Parlak, H.Karabaş, İ.Ozsert, V.Ayhan, I.Cesur, "Application of Taguchi's methods to investigate factors affecting emissions of a diesel engine running with tobacco oil seed methyl ester", Int. J. Vehicle Design, Vol. 59, Nos. 2/3, 2012.

[17]. D.Chandran, H.K.Ng, H.L.N.Lau, S.Gan, Y.M.Choo, "Investigation of the effects of palm biodiesel dissolved oxygen and conductivity on metal corrosion and elastomer degradation under novel immersion method", Applied Thermal Engineering, vol. 104, pp. 294-308, 2016. [18]. M.Gürü, A.Koca, Ö. Can, C.Çınar, F.Şahin, "Biodiesel production from waste chicken fat based sources and evaluation with $\mathrm{Mg}$ based additive in a diesel engine, Renew", Energy, vol. 35, no.3, pp. 637-643, 2010.

[19]. A.N.Ozsezen, M.Canakci, "An investigation of the effect of methyl ester produced from waste frying oil on the performance and emissions of an IDI diesel engine", J. Fac.Eng. Arch. Gazi Univ. Vol. 23 no.2, pp. 395-404, 2008. [20]. E.Özturk, "Performance, emissions, combustion and injection characteristics of a diesel engine fuelled with canola oil-hazelnut soapstock biodiesel mixture", Fuel Processing Technology, vol.129, pp. 183-191, 2015

[21]. Ö.Can, "Combustion characteristics, performance and exhaust emissions of a diesel engine fueled with a waste cooking oil biodiesel mixture", Energy Convers. Manag., vol. 87, pp. 676-686, 2014.

[22]. A.K.Agarwal, L.Das, "Biodiesel development and characterization for use as a fuel in compression ignition engines", Journal of Enginering Gas Turbines Power, vol. 123, pp. 123:440-447, 2007.

[23]. C.A.Sharp, T.W.Ryan, G.Knothe, "Heavy-duty diesel engine emissions tests using special biodiesel fuels", SAE Technical Paper, 2005.

[24]. J.Suryawanshi, N.Deshpande, "Overview of EGR, injection timing and pressure on emissions and performance of CI engine with pongamia methyl ester", SAE Techincal Paper, 2005.

[25]. M.B.Sirman, E.C.Owens, K.A.Whitney, "Emissions comparison of alternative fuels in an advanced automotive diesel engine", SAE Technical Paper, 2000.

[26]. Yücesu, H.S., Altın, R., Çetinkaya, S., "Dizel Motorlarında alternatif yakıt olarak bitkisel yağ kullanımının deneysel incelenmesi", Turkish Journal of Engineerıng and Environmental Sciences, vol. 25, pp. 39-49, 2001.
[27]
C. D. Rakopoulos,
D. C. Rakopoulos,

D. T. Hountalas, E. G. Giakoum is, E. C. Andr itsak is, "Performance and emissions of bus engine using blends of diesel fuel with bio-diesel of sunflower or cottonseed oils derived from Greek feedstock", Fuel, vol. 87, pp. 147-157, 2008.
[28]
C. Kaplan,
R. Arsian,
A. Surmen,

"Performance Characteristics of Sunflower Methyl Esters as Biodiesel", Energy Sources, Part A, vol. 28, pp. 751-755, 2006. 